\title{
Intraoperative bypass graft flow in intra-aortic balloon pump-supported patients: Differences in arterial and venous sequential conduits
}

\author{
Francesco Onorati, MD, Giuseppe Santarpino, MD, Antonio Rubino, MD, Lucia Cristodoro, MD, \\ Cristian Scalas, MD, and Attilio Renzulli, MD, PhD
}

\begin{abstract}
Background: The intra-aortic balloon pump is used worldwide as an anti-ischemic strategy. However, little is known about the modifications of the graft flowmetry during use of intra-aortic balloon pump.

Methods: An observational study aimed at analyzing transit-time flow measurements during 1:1 intra-aortic balloon pump use and during its cessation in 138 consecutive patients using intra-aortic balloon pump before coronary artery bypass grafting $(n=442$ graft segments) was reported.

Results: In normally functioning grafts, the mean diastolic and mean blood flow improved significantly during 1:1 intra-aortic balloon pump use compared with during intra-aortic balloon pump cessation $(P<.001)$, although mean and diastolic arterial pressures were significantly lower $(P=.001)$. Arterial and sequential saphenous vein grafts showed greater improvements in mean diastolic and mean flow compared with single venous grafts. Surplus graft flow (defined as mean flow during 1:1 intra-aortic balloon pump use/mean flow with intra-aortic balloon pump off) was recorded (surplus graft flow $>1$ ) during 1:1 intra-aortic balloon pump use in all normally functioning grafts, with higher values in single arterial or sequential saphenous vein grafts versus single venous grafts (both $P<.001$ ). In the 9 cases of graft failure, the mean diastolic, mean systolic, and mean flow were significantly lower and the pulsatility index greater, compared with normally functioning grafts (all $P \leq .001$ ). Blood flow did not change appreciably during 1:1 intra-aortic balloon pump use in failed bypass grafts; thus the surplus graft flow approached 1.
\end{abstract}

Conclusion: In this analysis, use of intra-aortic balloon pump was associated with improved diastolic and mean blood flow in bypass grafts. Arterial and sequential grafts were associated with greater improvements in blood flow and surplus graft flow. Graft failure was associated with poor transit-time flow results, high pulsatility index values, and absent surplus graft flow.

Intra-aortic balloon pump (IABP) use is a common anti-ischemic strategy employed in the daily practice. ${ }^{1}$ Reductions in IABP-related complications with the use of small catheters and sheathless techniques ${ }^{2}$ have spurred the more liberal use of preoperative IABP support in high-risk coronary artery bypass grafting $(\mathrm{CABG})^{2,3}$ Although the main effects of IABP have been purported to be a decrease in myocardial oxygen consumption and an increase in coronary perfusion through diastolic augmentation, few studies have investigated the effects of the IABP on CABG flowmetry. ${ }^{4-7}$ In some animal models, diastolic blood flow in the internal thoracic artery and descending aorta coronary bypass grafts has increased less than in the native left anterior descending coronary artery (LAD) and ascending aorta-coronary grafts during left ventricular assistance, particularly by means of

From the Cardiac Surgery Unit, Magna Graecia, University of Catanzaro, Italy. Received for publication Aug 28, 2008; revisions received Oct 30, 2008; accepted for publication Nov 26, 2008.

Address for reprints: Francesco Onorati, MD, Cardiac Surgery Unit, Magna Graecia University, Catanzaro, Italy (E-mail: frankono@libero.it).

J Thorac Cardiovasc Surg 2009;138:54-61

$0022-5223 / \$ 36.00$

Copyright (c) 2009 by The American Association for Thoracic Surgery doi:10.1016/j.jtcvs.2008.11.044
IABP. ${ }^{4}$ Another animal study has shown improved blood flow in both internal thoracic artery and venous conduits, but only when the IABP was placed in the ascending aorta-no such effect was noted when the device was placed in the descending thoracic aorta, as occurs in clinical practice. ${ }^{5}$ Still others have reported an anecdotal case of reduced blood flow in descending aorta coronary grafts with the use of IABP. ${ }^{6}$ A recent report of a small series of patients requiring IABP support showed no increase in diastolic pressure in the native coronary circulation distal to the site of stenosis, indicating that the major effect of IABP use in high-risk patients relates more to reductions in oxygen demand by systolic unloading than to diastolic augmentation of coronary blood flow. ${ }^{7}$

The aim of the present observational study was to investigate the effects of preoperative IABP assistance on blood flow within coronary bypass grafts among patients having CABG during a 3 -year period at a single academic institution.

\section{METHODS \\ Patients \\ We analyzed data from patients who had CABG at our institution and who also received preoperative IABP support. Preoperative IABP use}




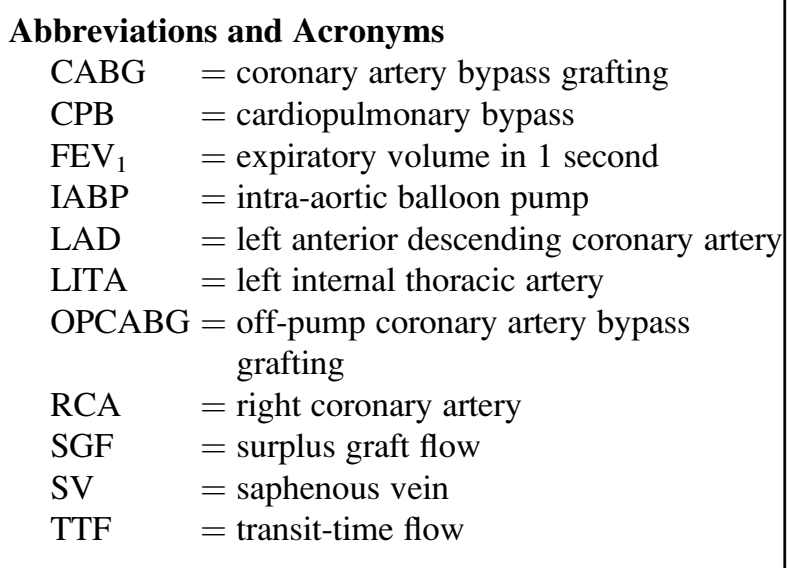

was indicated for patients with 3 -vessel disease and $\geq 2$ of the following: preoperative left ventricular ejection fraction $\leq 30 \%$, left main coronary artery stem stenosis $>90 \%$, chronic occlusion of the 3 main coronary trunks (LAD, right, and circumflex coronary arteries), tight stenosis ( $>95 \%$ ) of the proximal LAD (before the first septal or diagonal branch), proximal tight stenosis $(>95 \%)$ of a dominant right coronary artery (RCA) with remote branches for the posterior wall of the left ventricle, unstable angina despite the use of intravenous nitrates and heparin, recent ( $<7$ days) acute myocardial ischemia of the anterolateral left ventricular wall, and acute ongoing angina or myocardial ischemia with failed percutaneous coronary intervention.

\section{Surgical Technique}

Surgery was performed through a median sternotomy by 2 of the 4 authors. The left internal thoracic artery (LITA) was harvested with low-voltage $(20 \mathrm{mV})$ cautery, and side branches were clipped. Proximal dissection was performed above the first rib. The LITA was anastomosed to the LAD. The radial artery (RA) was harvested, after obtaining a negative Allen test, with the aid of a harmonic scalpel (Ethicon Endo-Surgery, Cincinnati, Ohio), using the variable mode at moderate intensity. Major collateral branches were controlled with small clips. The RA was used only as a free graft and was proximally anastomosed to the ascending aorta. All arterial grafts were secured with 2 epicardial stitches using 6-0 polypropylene on both sides after completion of distal anastomoses.

Saphenous vein (SV) conduits were harvested from the best internal SV as detected by preoperative echo Doppler scanning. The SV conduits were never used to construct Y-conduits with the LITA; circumflex and RCA were the target territories. Single or sequential RA and SV grafting was left to the surgeon's discretion.

When cardiopulmonary bypass (CPB) was used, the ascending aorta was used as the arterial cannulation site. Venous return to the CPB machine was accomplished through a double-caval cannulation, when associated mitral surgery was done, or through a double-stage cannula into the right atrium in all other cases. Proximal anastomoses were done either after aortic crossclamp removal (when CPB was employed) or before distal anastomoses (when off-pump CABG [OPCABG] was performed). The use of CPB was standardized and included a Dideco tubing set (Mirandola, Modena, Italy), a 40- $\mu \mathrm{m}$ filter, a Stockert roller pump (Stockert Instrumente, Munich, Germany), and a hollow-fiber membrane oxygenator (Monolyth, Sorin Biomedica, Saluggia, Italy). Heparin $(300 \mathrm{U} / \mathrm{kg})$ was given to achieve a target activated clotting time $>480 \mathrm{~s}$. Systemic temperature was kept between $32^{\circ} \mathrm{C}$ and $34^{\circ} \mathrm{C}$. Myocardial protection during CPB was achieved with intermittent antegrade and retrograde hyperkalemic warm blood cardioplegia. Total CPB flow was maintained at $2.6 \mathrm{~L} \cdot \mathrm{min}^{-1} \cdot \mathrm{m}^{-2}$.
TABLE 1. Characteristics of the cohort

\begin{tabular}{|c|c|}
\hline Characteristic & $(\mathbf{n}=138)$ \\
\hline \multicolumn{2}{|l|}{ Baseline } \\
\hline Mean age (y) & $72.1 \pm 9.3$ \\
\hline Male sex & $103(74.6)$ \\
\hline Diabetes mellitus & $74(53.6)$ \\
\hline Hypertension & $87(63.0)$ \\
\hline Dyslipidemia & $71(51.4)$ \\
\hline Chronic obstructive pulmonary disease & $83(60.1)$ \\
\hline Prior myocardial infarction ( $>4 \mathrm{wk})$ & $66(47.8)$ \\
\hline Myocardial infarction within previous $7 \mathrm{~d}$ & $67(48.6)$ \\
\hline Anterolateral infarction & $50(36.2)$ \\
\hline \multicolumn{2}{|l|}{ Left ventricular ejection fraction } \\
\hline$<30 \%$ & $35(25.3)$ \\
\hline $30 \%-50 \%$ & $76(55.1)$ \\
\hline$>50 \%$ & $27(19.6)$ \\
\hline Left main stem stenosis $>90 \%$ & $55(39.9)$ \\
\hline Chronic occlusion, 3 main trunks & $39(28.3)$ \\
\hline Proximal LAD stenosis $>95 \%$ & $75(54.3)$ \\
\hline Proximal dominant RCA stenosis $>95 \%$ & $73(52.9)$ \\
\hline Refractory unstable angina* & $77(55.8)$ \\
\hline $\begin{array}{l}\text { Ongoing infarction or angina; failed percutaneous } \\
\text { intervention }\end{array}$ & $40(29.0)$ \\
\hline \multicolumn{2}{|l|}{ TIMI score } \\
\hline LAD & $0.67 \pm 0.77$ \\
\hline Circumflex artery & $0.97 \pm 0.75$ \\
\hline $\mathrm{RCA}$ & $0.88 \pm 0.81$ \\
\hline \multicolumn{2}{|l|}{ Intraoperative } \\
\hline Off-pump bypass grafting & $31(22.4)$ \\
\hline Mitral valvuloplasty & $56(40.6)$ \\
\hline Tricuspid valvuloplasty & $23(16.7)$ \\
\hline Carotid thromboendarterectomy & $11(8.0)$ \\
\hline Minimally invasive ablation for atrial fibrillation & $31(22.5)$ \\
\hline Aortic crossclamp time (min) & $69.5 \pm 22.8$ \\
\hline Cardiopulmonary bypass time (min) & $112.8 \pm 35.6$ \\
\hline \multicolumn{2}{|l|}{ Postoperative } \\
\hline Intensive therapy unit stay (h) & $44.2 \pm 22.7$ \\
\hline Hospital stay $(\mathrm{d}) \dagger$ & $7.3 \pm 3.9$ \\
\hline
\end{tabular}

Data are presented as number (percentage) of patients or mean \pm standard deviation. $L A D$, Left anterior descending coronary artery; $R C A$, right coronary artery; TIMI, Thrombolysis In Myocardial Infarction. *Despite treatment with intravenous nitrates, heparin, or both. †Starting from the day of bypass surgery.

Exposure and stabilization during OPCABG were achieved with the Octopus-IV tissue stabilizer (Medtronic Inc, Minneapolis, Minn). Lateral wall vessels were exposed with the aid of the Starfish system (Medtronic Inc). Visualization was enhanced by use of a surgical blower-humidifier (model SSVW-002, Surgical Site Visualization Wand, Research Medical, Midvale, $\mathrm{Utah}$ ) connected to a regulated $\mathrm{CO}_{2}$ source. Intracoronary shunts were routinely used, and OPCABG was not performed with the aid of coronary snaring. When OPCABG was performed, the first grafted vessel was always the $\mathrm{LAD}$, followed by proximal anastomoses with the $\mathrm{SV}$ or RA, and then distal anastomoses.

Patients having OPCABG received heparin (150 U/kg) to achieve an activated clotting time $>300 \mathrm{~s}$. Protamine was given at the end of surgery to reverse the anticoagulant effects of heparin. Blood was recovered intraoperatively by means of an autotransfusion device (Autotrans Dideco, Mirandola, Modena, Italy) in all cases. Blood transfusion was indicated for a hemoglobin level $<8 \mathrm{~g} / \mathrm{dL}$. After surgery, patients received anticoagulation with enoxaparin, with a target activated partial thromboplastin time $>40 \mathrm{~s}$, 
TABLE 2. TTF results during 1:1 IABP and during temporary IABP cessation, by type of bypass graft (433 functioning CABGs)

\begin{tabular}{|c|c|c|c|c|}
\hline & IABP cessation & IABP 1:1 & $\boldsymbol{P}$ & Improvement, $\%(95 \% \mathrm{CI})$ \\
\hline \multicolumn{5}{|l|}{ Single saphenous vein-OM $(n=47)$} \\
\hline Mean diastolic blood flow (mL/min) & $38.6 \pm 12.4$ & $73.8 \pm 11.7$ & $<.001$ & $84.2 \%(74.1 \%-92.8 \%)$ \\
\hline Mean flow $(\mathrm{mL} / \mathrm{min})$ & $20.1 \pm 11.1$ & $30.8 \pm 16.1$ & $<.001$ & $53.2 \%(49.4 \%-57.1 \%)$ \\
\hline Mean systolic flow (mL/min) & $11.1 \pm 8.6$ & $9.9 \pm 7.7$ & .473 & $-1.1 \%(-3.4 \%-0.5 \%)$ \\
\hline Pulsatility index & $1.76 \pm 0.65$ & $3.49 \pm 0.66$ & $<.001$ & \\
\hline \multicolumn{5}{|c|}{ Single saphenous vein-RCA territory $(\mathrm{n}=55)$} \\
\hline Mean diastolic flow (mL/min) & $37.2 \pm 10.6$ & $78.9 \pm 17.9$ & $<.0001$ & $135.2 \%(95.4 \%-172.6 \%)$ \\
\hline Mean flow $(\mathrm{mL} / \mathrm{min})$ & $23.1 \pm 7.5$ & $34.7 \pm 10.8$ & $<.001$ & $49.2 \%(45.4 \%-52.9 \%)$ \\
\hline Mean systolic flow (mL/min) & $10.2 \pm 6.8$ & $9.5 \pm 5.5$ & .455 & $-1.3 \%(-2.8 \%-0.4 \%)$ \\
\hline Pulsatility index & $1.67 \pm 0.74$ & $3.63 \pm 0.60$ & $<.001$ & \\
\hline \multicolumn{5}{|l|}{ Sequential saphenous vein $(\mathrm{n}=88)^{*}$} \\
\hline Mean diastolic flow (mL/min) & $69.6 \pm 33.8$ & $156.9 \pm 73.9$ & $<.001$ & $128.7 \%(11.2 \%-173.9 \%$ \\
\hline Mean flow $(\mathrm{mL} / \mathrm{min})$ & $48.1 \pm 23.9$ & $89.4 \pm 45.4$ & $<.001$ & $85.8 \%(82.2 \%-89.4 \%)$ \\
\hline Mean systolic flow (mL/min) & $13.1 \pm 8.7$ & $12.4 \pm 7.8$ & .419 & $-0.4 \%(-1.0 \%-0.5 \%)$ \\
\hline Pulsatility index & $1.58 \pm 0.64$ & $3.45 \pm 0.74$ & $<.001$ & \\
\hline \multicolumn{5}{|l|}{ LITA-LAD $(\mathrm{n}=136)$} \\
\hline Mean diastolic flow (mL/min) & $54.9 \pm 22.5$ & $135.7 \pm 52.1$ & $<.001$ & $133.4 \%(108.2 \%-173.2 \%)$ \\
\hline Mean flow (mL/min) & $30.7 \pm 17.8$ & $58.5 \pm 34.2$ & $<.001$ & $89.9 \%(86.5 \%-93.5 \%)$ \\
\hline Mean systolic flow (mL/min) & $10.8 \pm 8.3$ & $11.0 \pm 9.3$ & .587 & $0.5 \%(-0.2 \%-1.2 \%)$ \\
\hline Pulsatility index & $1.49 \pm 0.52$ & $3.71 \pm 0.68$ & $<.001$ & \\
\hline \multicolumn{5}{|l|}{ Radial artery-OM $(\mathrm{n}=46)$} \\
\hline Mean diastolic flow (mL/min) & $62.3 \pm 29.3$ & $145.9 \pm 62.7$ & $<.0001$ & $130.3 \%(106.2 \%-172.4 \%)$ \\
\hline Mean flow $(\mathrm{mL} / \mathrm{min})$ & $37.2 \pm 14.6$ & $71.4 \pm 26.8$ & $<.001$ & $92.5 \%(86.3 \%-98.8 \%)$ \\
\hline Mean systolic flow (mL/min) & $12.2 \pm 7.2$ & $11.0 \pm 13.8$ & .523 & $-0.2 \%(-1.3 \%-0.03 \%)$ \\
\hline Pulsatility index & $1.73 \pm 0.74$ & $3.83 \pm 0.68$ & $<.001$ & \\
\hline \multicolumn{5}{|l|}{ Radial artery-RCA territory $(n=41)$} \\
\hline Mean diastolic flow (mL/min) & $63.4 \pm 20.8$ & $149.6 \pm 51.1$ & $<.001$ & $134.2 \%(78.9 \%-167.3 \%)$ \\
\hline Mean flow $(\mathrm{mL} / \mathrm{min})$ & $39.5 \pm 13.7$ & $74.0 \pm 24.6$ & $<.001$ & $87.2 \%(80.4 \%-93.9 \%)$ \\
\hline Mean systolic flow (mL/min) & $16.8 \pm 9.4$ & $14.9 \pm 10.2$ & .235 & $-0.5 \%(-1.8 \%-0.6 \%)$ \\
\hline Pulsatility index & $1.85 \pm 0.68$ & $3.78 \pm 0.72$ & $<.001$ & \\
\hline \multicolumn{5}{|l|}{ Sequential radial artery $(\mathrm{n}=20)^{*}$} \\
\hline Mean diastolic flow (mL/min) & $90.6 \pm 35.3$ & $221.4 \pm 61.8$ & $<.001$ & $167.3 \%(99.4 \%-187.3 \%)$ \\
\hline Mean flow (mL/min) & $58.3 \pm 23.5$ & $109.6 \pm 46.3$ & $<.001$ & $87.3 \%(82.3 \%-92.4 \%)$ \\
\hline Mean systolic flow (mL/min) & $18.3 \pm 8.1$ & $17.1 \pm 9.4$ & .287 & $-0.4 \%(-1.5 \%-0.8 \%)$ \\
\hline Pulsatility index & $1.61 \pm 0.66$ & $3.44 \pm 0.84$ & $<.001$ & \\
\hline
\end{tabular}

$C A B G$, Coronary artery bypass graft; $C I$, confidence interval; $I A B P$, intra-aortic balloon pump; $L A D$, left anterior descending coronary artery; $L I T A$, left internal thoracic artery; $O M$, obtuse marginal branches of the left circumflex artery; $R C A$, right coronary artery; $T T F$, transit-time flow. *Onto the left circumflex and right coronary artery territories.

starting when postoperative bleeding was controlled (usually within 6 hours) and continuing until postoperative day 3 . Aspirin $(150 \mathrm{mg})$ was given daily beginning on postoperative day 3 .

\section{IABP Assistance, Flowmetric Analysis, and Evaluation of Surplus Graft Flow}

To better support hemodynamic function before CABG, institutional policy called for percutaneous insertion of IABP with the sheathless technique (7F to $7.5 \mathrm{~F}$; 34 or $40 \mathrm{~mL}$ according to the body surface area; balloon, Datascope Corp, Fairfield, NJ) through the best femoral artery before induction of anesthesia, with connection to a Datascope pump (Datascope Corp). ${ }^{8,9}$ Correct placement of IABP was assessed by postoperative chest radiograph or transesophageal echocardiography. In 12 patients $(8.7 \%)$, because of severe peripheral disease of the aortic bifurcation, iliac arteries, or femoral arteries, IABP was percutaneously introduced under fluoroscopic guidance with the sheathless technique through the best brachial artery. ${ }^{9}$ IABP was withdrawn when hemodynamic stability was restored, defined as a cardiac index $\geq 2.0 \mathrm{~L} \cdot \mathrm{m}^{-2} \cdot \mathrm{min}^{-1}$ with only minimal inotropic support (dobutamine or enoximone at $5 \mu \mathrm{g} \cdot \mathrm{kg}^{-1} \cdot \mathrm{min}^{-1}$ ).
It was the aim of this observational study to evaluate the graft flowmetry during IABP support and during its temporary cessation (control). The Institutional Review Board approved (December 2004) this study, and individual consent was obtained in all patients. The transit-time method is based on the fact that the time required for ultrasound to pass through blood is slightly longer upstream than downstream. As the ultrasound beam is wider than the diameter of the vessel lumen, the ultrasound wave will cover every flow vector in the vessel, thus making the transit-time difference proportional to the true volume of blood flow in milliliters per minute. ${ }^{10} \mathrm{Graft}$ function was assessed under stable hemodynamic conditions, generally 30 minutes after protamine administration. Flowmetry of the grafts was performed with a transit-time flowmeter (HT313, Transonic, Transonic Systems Inc, Ithaca, NY). Different probe sizes $(2,2.5$, or $3 \mathrm{~mm})$ were available to avoid distortion or compression of grafts. Skeletonization of a small segment of the RA and of the LITA was necessary to reduce the quantity of tissue interposed between the vessel and the probe. The curves were always coupled with the electrocardiogram tracing to differentiate systolic from diastolic flow. The following variables were calculated: mean systolic, mean diastolic, and mean flow (expressed in $\mathrm{mL} / \mathrm{min}$ ), directly 


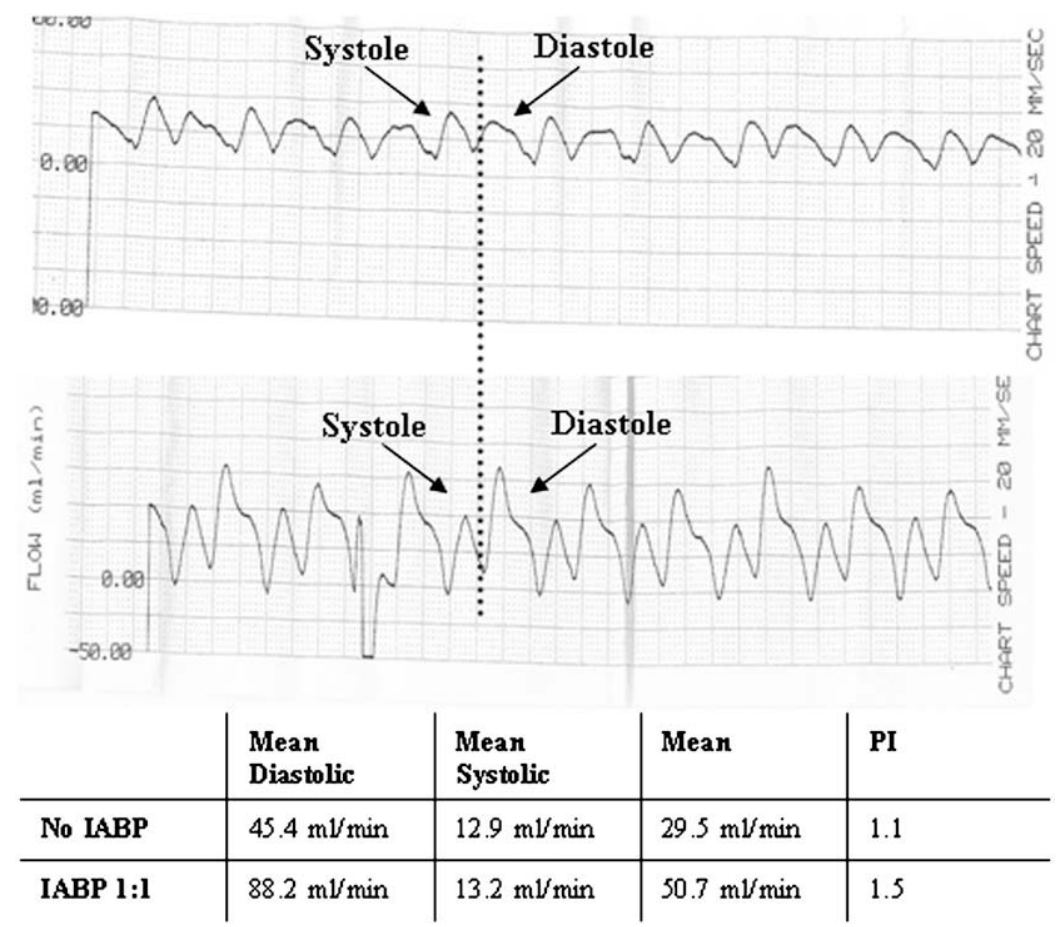

FIGURE 1. Example of improvement in a sequential saphenous coronary artery bypass graft of the mean diastolic and of the mean graft flow by $1: 1$ intraaortic balloon pump $(I A B P ; A)$ compared with baseline (No IABP;B).

derived from the flowmeter, and pulsatility index (derived from maximum diastolic flow - minimum systolic flow/mean flow). The flow pattern (systolic, diastolic) was directly derived from the flow curve of the trace. ${ }^{10}$ Data from single, sequential, arterial, and venous conduits were recorded. To evaluate the potential of IABP to recruit surplus graft flow (SGF), transittime flow (TTF) measurements were recorded both during 1:1 IABP support and following 5 minutes of temporary cessation ("IABP off"). Thus patients served as their own controls. Systolic, diastolic, and mean arterial pressures were recorded and compared during 1:1 IABP support and during its temporary cessation. Percent improvements in mean systolic, mean diastolic, and mean blood flows were calculated. The SGF was calculated from the mean flow occurring during 1:1 IABP support divided by the mean flow during temporary cessation. ${ }^{10}$

\section{Data Collection and Definitions}

The following definitions were used: for angina, Canadian Cardiovascular Society grading; hypertension, systolic blood pressure $>140 \mathrm{~mm} \mathrm{Hg}$, diastolic blood pressure $>90 \mathrm{~mm} \mathrm{Hg}$, or both, or ongoing treatment with antihypertensive medication; diabetes mellitus, fasting blood glucose $>$ $140 \mathrm{mg} / \mathrm{dL}$ on $\geq 2$ occasions or the use of antidiabetic medication (oral drugs or insulin); chronic obstructive pulmonary disease, Summit database definitions (treatment for chronic pulmonary compromise or a forced expiratory volume in 1 second $\left[\mathrm{FEV}_{1}\right]<75 \%$ of the predicted value or $\mathrm{FEV}_{1} /$ forced vital capacity $<0.7$ ); and left main stem disease, $>50 \%$ obstruction in the left main coronary artery stem.

Hospital mortality was defined as death occurring $\leq 30$ days after surgery; perioperative acute myocardial ischemia, as new $\mathrm{Q}$ waves $>0.04$ $\mathrm{ms}$, reduction in $\mathrm{R}$ waves $>25 \%$ in $\geq 2$ leads, or both along with new akinetic/dyskinetic segment identified on echocardiography and a peak troponin I level $\geq 3.1 \mu \mathrm{g} / \mathrm{L}$ at 12 hours after surgery ${ }^{11}$; low-output syndrome, as hemodynamic compromise or cardiac index $<2.0 \mathrm{~L} / \mathrm{min} / \mathrm{m}^{2}$ in the intensive therapy unit despite IABP assistance and inotropic support, after correction of all electrolyte and blood-gas abnormalities, and after adjusting the pre- load to its optimal value; respiratory failure, as the need for mechanical ventilation for $>48$ hours or for noninvasive ventilation with positive end-expiratory pressure for $>24$ hours; acute renal failure, as the need for continuous venovenous hemofiltration or dialysis; and neurologic complication, as any focal brain lesion confirmed by clinical findings, computed tomography, or both or diffuse postoperative encephalopathy, convulsions, or severely altered mental status. Hospital morbidity was defined as any complication requiring therapy or causing delayed hospital or intensive therapy unit discharge.

\section{Statistical Analysis}

All data were prospectively recorded by means of the institutional database. Statistical analysis was performed with use of the SPSS program for Windows, version 13.0 (SPSS Inc, Chicago, Ill). Continuous variables are presented as means \pm standard deviation, and categorical variables are presented as number (percentage) of patients unless otherwise indicated. Data were checked for normality before analysis. The paired-sample $t$ test was used to evaluate differences in continuous variables during 1:1 IABP support versus during its temporary cessation ('IABP-off'). One-way analysis of variance was used to evaluate the significance of differences among types of bypass grafts. If the $\mathrm{F}$ value was significant and variance was homogeneous, Tukey's multiple comparison test was used to assess differences between individual graft types; otherwise, Tamhane's T2 test was used. Two-way analysis of variance for repeated measures was used for comparisons within (1:1 IABP vs IABP-off) and between groups (normal-functioning versus failed grafts). Categorical variables were analyzed with use of either the $\chi^{2}$ test or Fischer exact test.

\section{RESULTS}

\section{Patient Population}

Between January 2005 and January 2008, 714 consecutive patients had CABG at our institution. Of these, 138 
received IABP preoperatively. The cohort was typical of an older, high-risk CABG population receiving IABP support, with high prevalences of diabetes, hypertension, chronic lung disease, and left ventricular dysfunction (Table 1).

A total of 442 grafts on 551 distal anastomoses (109 sequential grafts, 333 single grafts) were completed. The itemization of graft types for successful procedures is shown in Table 2. The mean number of grafts per patient was 3.99 (minimum, 3; maximum, 5).

\section{TTF Analysis and GFR}

Among the different types of grafts, mean systolic blood flow did not change significantly during times of 1:1 IABP assistance versus IABP cessation. The mean diastolic flow and mean flow, however, significantly improved with IABP assistance (Table 2 ), with values increasing by $84 \%$ to $167 \%$ and $49 \%$ to $92 \%$, respectively, among the various graft types. Waveform analysis of well-functioning grafts always ruled out that the increase of flow observed with IABP mainly resulted from an increase of the diastolic flow (Figure 1).

During both 1:1 IABP and IABP cessation, TTF analysis was accomplished at the same systolic arterial pressures $(104.2 \pm 11.7 \mathrm{~mm} \mathrm{Hg}$ and $104.0 \pm 11.8 \mathrm{~mm} \mathrm{Hg}$, respectively; $P=.168$ ). However, the diastolic mean and mean flows on TTF analysis were higher during 1:1 IABP support versus IABP cessation, despite the presence of slightly lower diastolic and mean arterial pressures (diastolic pressure during TTF, $61.7 \pm 14.0 \mathrm{~mm} \mathrm{Hg}$ during 1:1 IABP versus $63.5 \pm$ $14.3 \mathrm{~mm} \mathrm{Hg}$ during IABP cessation; $P<.001$; mean arterial pressure during TTF, $75.8 \pm 9.4 \mathrm{~mm} \mathrm{Hg}$ during 1:1 IABP versus $77.0 \pm 9.5 \mathrm{~mm} \mathrm{Hg}$ during IABP cessation; $P<.001$ ).

SGF was recruited (SGF $>1$ ) during 1:1 IABP in all normally functioning grafts (Table 3 ), with significantly higher SGF noted in arterial versus SV grafts and in sequential versus single grafts.

There were 9 cases of failed CABG, each of which was responsible for perioperative myocardial ischemia (see Hospital Outcomes, below). Among these grafts, the mean diastolic, mean systolic, and mean blood flow rates were significantly lower than those among normally functioning grafts (Table 4). Moreover, the failed grafts showed no improvement in blood flow during 1:1 IABP (Tables 4 and 5) and a corresponding lack of SGF (Table 5). In all these patients, the detection of poor TTF findings was associated with corresponding ischemic electrocardiogram and/or echocardiographic signs (new akinetic or hypokinetic segments) of the corresponding myocardial territories. However, we never redid distal anastomoses in all of them, due to the "expected" poor TTF results (poor distal vessel quality with diffuse and severe calcified lesions at preoperative angiography).

\section{Hospital Outcomes}

Two patients $(1.4 \%)$ died during hospitalization, 9 patients $(6.5 \%)$ had perioperative acute myocardial ischemia,
TABLE 3. Comparison of SGF in normally functioning bypass grafts, by graft type

\begin{tabular}{|c|c|c|}
\hline Type of CABG & SGF & $\begin{array}{l}P \text { values } \\
\text { (post-hoc } \\
\text { analysis) }\end{array}$ \\
\hline Single saphenous vein-OM $(n=47)$ & $1.53 \pm 0.27$ & \\
\hline Single saphenous vein-RCA territory & & .971 \\
\hline Sequential saphenous vein & & $<.001$ \\
\hline LITA-LAD & & $<.001$ \\
\hline Radial artery-OM & & $<.001$ \\
\hline Radial artery-RCA territory & & $<.001$ \\
\hline Sequential radial artery & & $<.001$ \\
\hline Single saphenous vein-RCA territory $(\mathrm{n}=55)$ & $1.49 \pm 0.19$ & \\
\hline Single saphenous vein-RCA territory & & .971 \\
\hline Sequential saphenous vein & & $<.001$ \\
\hline LITA-LAD & & $<.001$ \\
\hline Radial artery-OM & & $<.001$ \\
\hline Radial artery-RCA territory & & $<.001$ \\
\hline Sequential radial artery & & $<.001$ \\
\hline Sequential saphenous vein $(\mathrm{n}=88)^{*}$ & $1.85 \pm 0.35$ & \\
\hline Single saphenous vein-OM & & $<.001$ \\
\hline Single saphenous vein-RCA territory & & $<.001$ \\
\hline LITA-LAD & & .831 \\
\hline Radial artery-OM & & .657 \\
\hline Radial artery-RCA territory & & .994 \\
\hline Sequential radial artery & & .999 \\
\hline LITA-LAD $(\mathrm{n}=136)$ & $1.89 \pm 0.33$ & \\
\hline Single saphenous vein-OM & & $<.001$ \\
\hline Single saphenous vein-RCA territory & & $<.001$ \\
\hline Sequential saphenous vein & & .831 \\
\hline Radial artery-OM & & .995 \\
\hline Radial artery-RCA territory & & .993 \\
\hline Sequential radial artery & & .999 \\
\hline Radial artery-OM $(\mathrm{n}=46)$ & $1.92 \pm 0.34$ & \\
\hline Single saphenous vein-OM & & $<.001$ \\
\hline Single saphenous vein-RCA territory & & $<.001$ \\
\hline Sequential saphenous vein & & .657 \\
\hline LITA-LAD & & .995 \\
\hline Radial artery-RCA territory & & .931 \\
\hline Sequential radial artery & & .980 \\
\hline Radial artery-RCA territory $(n=41)$ & $1.87 \pm 0.30$ & \\
\hline Single saphenous vein-OM & & $<.001$ \\
\hline Single saphenous vein-RCA territory & & $<.001$ \\
\hline Sequential saphenous vein & & .994 \\
\hline LITA-LAD & & .993 \\
\hline Radial artery-OM & & .931 \\
\hline Sequential radial artery & & .999 \\
\hline Sequential radial artery $(\mathrm{n}=20)^{*}$ & $1.87 \pm 0.31$ & \\
\hline Single saphenous vein-OM & & $<.001$ \\
\hline Single saphenous vein-RCA territory & & $<.001$ \\
\hline Sequential saphenous vein & & .999 \\
\hline LITA-LAD & & .999 \\
\hline Radial artery-OM & & .980 \\
\hline Radial artery-RCA territory & & .999 \\
\hline
\end{tabular}


TABLE 4. TTF results in failed $(n=9)$ bypass grafts, overall and by graft type

\begin{tabular}{|c|c|c|c|c|c|}
\hline & \multicolumn{3}{|c|}{ Failed grafts } & \multicolumn{2}{|c|}{ Successful grafts } \\
\hline & IABP cessation & IABP 1:1 & $\boldsymbol{P}$ & IABP cessation & $P^{*}$ \\
\hline \multicolumn{6}{|l|}{ All failed grafts $(\mathrm{n}=9)$} \\
\hline Mean diastolic flow $(\mathrm{mL} / \mathrm{min})$ & $6.5 \pm 3.2$ & $6.2 \pm 4.5$ & .343 & $83.5 \pm 21.7$ & $<.001$ \\
\hline Mean flow (mL/min) & $4.6 \pm 0.8$ & $4.7 \pm 0.9$ & .312 & $34.9 \pm 20.2$ & $<.001$ \\
\hline Mean systolic flow $(\mathrm{mL} / \mathrm{min})$ & $8.5 \pm 1.8$ & $8.1 \pm 1.5$ & .535 & $11.2 \pm 7.7$ & .042 \\
\hline \multicolumn{6}{|l|}{ Single saphenous vein-OM $(n=2)$} \\
\hline Mean diastolic flow (mL/min) & $5.0 \pm 2.2$ & $5.5 \pm 3.6$ & .585 & $38.6 \pm 12.4$ & $<.001$ \\
\hline Mean flow $(\mathrm{mL} / \mathrm{min})$ & $4.7 \pm 1.7$ & $5.1 \pm 1.8$ & .090 & $20.1 \pm 11.1$ & .001 \\
\hline Mean systolic flow (mL/min) & $7.4 \pm 2.6$ & $8.1 \pm 3.3$ & .217 & $11.1 \pm 8.6$ & .038 \\
\hline Pulsatility index & $5.4 \pm 0.6$ & $5.9 \pm 0.4$ & .205 & $1.76 \pm 0.65$ & $<.001$ \\
\hline \multicolumn{6}{|l|}{ Single saphenous vein-CA $(n=2)$} \\
\hline Mean diastolic flow (mL/min) & $6.0 \pm 1.4$ & $6.3 \pm 2.5$ & .223 & $37.2 \pm 10.6$ & $<.001$ \\
\hline Mean flow (mL/min) & $4.4 \pm 0.5$ & $4.3 \pm 0.1$ & .656 & $23.1 \pm 7.5$ & $<.001$ \\
\hline Mean systolic flow (mL/min) & $7.9 \pm 1.6$ & $8.1 \pm 5.5$ & .331 & $10.2 \pm 6.8$ & .041 \\
\hline Pulsatility index & $4.4 \pm 0.5$ & $5.2 \pm 0.3$ & .374 & $1.67 \pm 0.74$ & $<.001$ \\
\hline \multicolumn{6}{|l|}{ LITA-LAD $(\mathrm{n}=2)$} \\
\hline Maximum flow (mL/min) & $5.2 \pm 2.0$ & $5.4 \pm 4.2$ & .414 & $54.9 \pm 22.5$ & $<.001$ \\
\hline Mean flow (mL/min) & $3.7 \pm 0.6$ & $3.9 \pm 0.6$ & .205 & $30.7 \pm 17.8$ & $<.001$ \\
\hline Minimum flow (mL/min) & $8.2 \pm 0.5$ & $8.3 \pm 1.5$ & .505 & $10.8 \pm 8.3$ & .040 \\
\hline Pulsatility index & $5.7 \pm 0.1$ & $6.1 \pm 0.1$ & .090 & $1.49 \pm 0.52$ & $<.00$ \\
\hline
\end{tabular}

$I A B P$, Intra-aortic balloon pump; $L A D$, left anterior descending coronary artery; $L I T A$, left internal thoracic artery; $O M$, obtuse marginal branches of the left circumflex artery; $R C A$, right coronary artery; $T T F$, transit-time flow. *Compared with during IABP cession in failed bypass grafts.

and 11 patients $(8.0 \%)$ had postoperative low-output syndrome. The 9 cases of acute myocardial ischemia reflected failed grafting of a single $\mathrm{SV}$ on the RCA territory $(\mathrm{n}=$ 2 ), single $\mathrm{SV}$ on obtuse branches $(\mathrm{n}=2)$, sequential $\mathrm{SV}$ $(\mathrm{n}=1)$, LITA-to-LAD $(\mathrm{n}=2)$, single RA on the RCA territory $(\mathrm{n}=1)$, and single RA on the first obtuse marginal branch $(\mathrm{n}=1)$. These data were further confirmed by postoperative coronary angiographies, which were accomplished during the same hospitalization ( $n=3$ patients) or during the first 30 days ( $n=6$ patients) following surgery.

Twenty-three patients $(16.7 \%)$ required noninvasive ventilation because of respiratory insufficiency, 4 patients $(2.9 \%)$ had postoperative acute renal failure, and 2 patients $(1.4 \%)$ had neurologic complications. Except for 1 patient suffering from stroke, all of these patients recovered completely and were discharged home.

Three patients $(2.2 \%)$ had IABP-related complications, of which 2 were considered minor. The only major IABP- related complication was a case of brachial artery thrombosis in a patient with transbrachial support, which required immediate IABP withdrawal and embolectomy. The patient recovered completely, however, and was discharged home.

\section{DISCUSSION}

The main effects of IABP have been purported to be a decrease in myocardial oxygen demand through reduced afterload and ventricular wall stress and an increase in coronary perfusion through diastolic augmentation. ${ }^{1}$ The literature supports the former hypothesis, but the data on coronary (or possibly collateral) blood flow enhancement are inconsistent. $^{7,12-14}$ Yoshitani and coworkers ${ }^{7}$ recently reported a reduction in oxygen demand through decreased afterload, but no augmentation of diastolic coronary flow, by measuring intracoronary pressure distal to coronary stenosis in humans. Moreover, few data exist on the effects of IABP on flow within bypass grafts, most of which have been obtained

TABLE 5. Change in blood flow $(95 \% \mathrm{CI})$ and SGF in failed bypass grafts, by graft type

\begin{tabular}{|c|c|c|c|c|}
\hline & \multicolumn{3}{|c|}{ Change in blood flow } & \multirow[b]{2}{*}{ SGF } \\
\hline & Mean diastolic (\%) & Mean $(\%)$ & Mean systolic (\%) & \\
\hline Single saphenous vein-OM $(n=2)$ & $10.1(6.2-19.4)$ & $7.6(-4.5-19.7)$ & $13.2(8.5-17.5)$ & $1.08 \pm 0.01$ \\
\hline Single saphenous vein-RCA $(n=2)$ & $5(0.4-8.2)$ & $-2.9(-71.4-65.5)$ & $2.5(-2.2-15.2)$ & $0.97 \pm 0.08$ \\
\hline Sequential saphenous vein $(n=1)^{*}$ & 2.5 & -3.8 & 3.7 & 0.96 \\
\hline LITA-LAD $(n=2)$ & $3.5(-3.5-9.1)$ & $4.2(-9.2-27.6)$ & $1.5(-1.5-4.6)$ & $1.04 \pm 0.03$ \\
\hline Radial artery-OM $(\mathrm{n}=1)$ & 2.5 & 1.9 & 1.5 & 1.02 \\
\hline Radial artery-RCA $(\mathrm{n}=1)$ & 3.3 & 3.9 & 5.6 & 1.04 \\
\hline
\end{tabular}

$C I$, Confidence interval; $L A D$, left anterior descending coronary artery; $L I T A$, left internal thoracic artery; $O M$, obtuse marginal branches of the left circumflex artery; RCA, right coronary artery; $S G F$, surplus graft flow. *Both left circumflex and right coronary artery territories. 
from animal models. ${ }^{4,5,15}$ Tedoriya and coworkers ${ }^{4}$ have shown that diastolic flow in internal thoracic artery and descending aorta coronary grafts increased less than in native LAD and ascending aorta coronary grafts during left ventricular assistance in dogs, particularly with IABP. In another animal model, Gitter and colleagues ${ }^{5}$ showed that blood flow was improved in both internal thoracic artery and venous conduits when IABP was placed in the ascending aorta but not when placed in the descending thoracic aorta. Tsuchida and coworkers ${ }^{6}$ have reported a case of reduced flow with IABP placement in the descending aorta in a patient with a descending aorta coronary graft. One study in humans has shown increased blood flow in SV grafts with the aid of IABP, but this was parallel to an increase in mean aortic pressure. ${ }^{15}$

Our study showed an increase in bypass graft diastolic and mean blood flow during IABP as used in clinical practice, with no increase in mean systemic arterial pressure. Accordingly, IABP assistance appears to increase diastolic (and therefore mean) graft flow parallel to a reduction in afterload, as confirmed by reduced systemic diastolic pressure. Moreover, the absence of SGF recruitment appears to be an early marker of graft malfunction. Under hypoxic conditions, myocardial performance depends on flow in the coronary arteries and/or bypass grafts. ${ }^{16,17}$ During cardiogenic shock, isolated reduction of afterload does not significantly improve myocardial function-enhanced coronary driving pressure, and therefore perfusion, are necessary to reverse ventricular failure. ${ }^{16,17}$ Further, treatment with inotropes and vasodilators (and inodilators) increase left ventricular work without increasing myocardial perfusion and actually reduce coronary flow by decreasing diastolic perfusion pressures. ${ }^{16,18}$ Again, our observational study showed significant increases in mean diastolic and mean blood flow in bypass grafts — without increases in mean systolic flowdespite concomitant reductions in systemic diastolic arterial pressure (afterload reduction) induced by IABP. Therefore, augmentation of diastolic blood flow can be purported to be one of the main effects of IABP in patients having $\mathrm{CABG}$, although experimental animal models with pressure-volume loops are necessary to better define such topic.

Our findings conflict with those of Tsuchida and colleagues ${ }^{6}$ and Kimura and coworkers, ${ }^{19}$ who noted that IABP use was not associated with improved coronary flow distal to sites of stenosis. Our results can be attributed to the fact that normally functioning bypass grafts, by definition, would circumvent mechanical obstructions to coronary flow caused by stenosis.

Internal thoracic artery grafts have been shown to carry the best long-term patency rates and provide the greatest survival and event-free survival benefits. ${ }^{20}$ Recent series also have shown that arterial revascularization improves outcomes of CABG, regardless of the type of arterial conduit. $^{1,10,21,22}$ Arterial grafting also may enhance resistance to the development of atherosclerosis, ${ }^{23}$ and it offers the possibility of ideal coronary-to-conduit size matching. ${ }^{24}$ Little is known about the intraoperative behavior of arterial grafts compared with SV grafts, however. TTF analysis with IABP provides an opportunity to explore the SGF associated with different types of bypass grafts.

In our study, the SGF was larger in arterial conduits than in single SV grafts. The principal determinant of the degree of patency late after CABG has been shown to be the rate of blood flow through the graft. Both Faulkner and associates ${ }^{25}$ and Rittgers and colleagues ${ }^{26}$ have reported a strict inverse association between flow rate and intimal proliferation. It can be speculated that the higher the flow, the longer the patency, although experimental studies are necessary to further investigate this topic.

The variables used to estimate flow rate are the diameter and resistance of the graft and the resistance posed by the native coronary vessel. Given that the diameters of SV grafts are relatively constant for a given patient and that the resistance posed by an SV graft is negligible compared with that of its coronary counterpart, the resistance of the native coronary vessels remains the principal determinant of flow rate. ${ }^{27}$ Thus if the individual resistance levels of the grafted arteries are assumed to be equivalent, a double sequential graft poses only half the resistance of an individual graft. Single SV grafts therefore would be more resistant than sequential conduits and would be expected to confer lesser patency than would sequential grafts. ${ }^{27}$ This hypothesis also explains the findings of $\mathrm{O}^{\prime} \mathrm{Neill}$ and colleagues ${ }^{27}$ and Grondin and coworkers, ${ }^{28}$ who found better patency with the proximal anastomoses of sequential grafts compared with the individual grafts. This same phenomenon would apply to consideration of sequential RA grafting.

In conclusion, IABP exerts a benefit in patients having CABG by improving diastolic blood flow through functioning bypass grafts, parallel to a reduction in afterload. However, experimental animal models with pressure-volume loops are necessary to clearly define the effects of IABP on cardiac work, oxygen consumption, and coronary resistances.

The combination of IABP and TTF technology can help in early detection of malfunctioning grafts through demonstration of the absence of SGF. Single arterial bypass grafts and sequential SV grafts were associated with greater SGF values than were single $S V$ grafts, offering a potential explanation for the survival advantage reported with these graft types.

\section{References}

1. Baskett RJ, Ghali WA, Maitland A, Hirsch GM. The intraaortic balloon pump in cardiac surgery. Ann Thorac Surg. 2002;74:1276-87.

2. Menon P, Totaro P, Youhana A, Argano V. Reduced vascular complication after IABP insertion using smaller catheter and sheathless technique. Eur J Cardiothorac Surg. 2002;22:491-2.

3. Gutfinger DE, Ott RA, Miller M, Selvan A, Codini MA, Alimadadian H, et al. Aggressive preoperative use of intraaortic balloon pump in elderly patients undergoing coronary artery bypass grafting. Ann Thorac Surg. 1999;67:610-3. 
4. Tedoriya T, Kawasuji M, Sakakibara N, Takemura H, Watanabe Y, Hetzer R. Coronary bypass flow during use of intraaortic balloon pumping and left ventricular assist device. Ann Thorac Surg. 1998;66:477-81.

5. Gitter R, Cate CM, Smart K, Jett GK. Influence of ascending versus descending balloon counterpulsation on bypass graft blood flow. Ann Thorac Surg. 1998;65: 365-70.

6. Tsuchida M, Yamato Y, Watanabe T, Ohzeki H, Hayashi J. Changes in graft flow pattern from the descending aorta due to intraaortic balloon pump. Ann Thorac Surg. 2000;70:981-2.

7. Yoshitani H, Akasaka T, Kaji S, Kawamoto T, Kume T, Neishi Y, et al. Effects of intraaortic balloon counterpulsation on coronary pressure in patients with stenotic coronary arteries. Am Heart J. 2007;154:725-31.

8. Onorati F, Presta P, Fuiano G, Mastroroberto P, Comi N, Pezzo F, et al. A randomized trial of pulsatile perfusion using an intraaortic balloon pump versus nonpulsatile perfusion on short-term changes in kidney function during cardiopulmonary bypass during myocardial reperfusion. Am J Kidney Dis. 2007;50:229-38

9. Onorati F, Impiombato B, Ferraro A, Comi MC, Spaccarotella C, Indolfi C, et al. Transbrachial intraaortic balloon pumping in severe peripheral atherosclerosis. Ann Thorac Surg. 2007;84:264-6.

10. Walpoth BH, Bosshard A, Genyk I, Kipfer B, Berdat PA, Hess OM, et al. Transittime flow measurement for detection of early graft failure during myocardial revascularization. Ann Thorac Surg. 1998;66:1097-100.

11. Onorati F, Pezzo F, Comi MC, Impiombato B, Esposito A, Polistina M, et al. Radial artery graft function is not affected by age. J Thorac Cardiovasc Surg. 2007; 134:1112-20

12. Bolooki H. Current status of circulatory support with intraaortic balloon pump. Cardiol Clin. 1985;3:123-33.

13. Flynn MS, Kern MJ, Donohue TJ, Aguirre FV, Bach RG, Caracciolo EA. Alterations of coronary collateral blood flow velocity during intraaortic balloon pumping. Am J Cardiol. 1993;71:1451-5.

14. Kern MJ, Aguirre F. Coronary flow alternans: a unique examination of coronary physiology and influence of intraaortic balloon pumping. Am Heart J. 1992;123: 1369-73.

15. Bolotin G, van der Veen FH, Lorusso R, Wolf T, Sachner R, Shofti R, et al. Hemodynamic analysis of descending versus ascending aortomioplasty, and comparison with intraaortic balloon pump. Eur J Cardiothorac Surg. 2002;21:975-80.
16. Bregman D, Kripke DC, Goetz RH. The effects of synchronous unidirectional intraaortic balloon pumping on hemodynamics and coronary blood flow in cardiogenic shock. Trans Am Soc Artif Intern Organs. 1970;16:439-46.

17. Kuhn LA, Kline HJ, Marano AJ, Hamby RI, Cestero J, Cohn LJ, et al. Mechanical increase of vascular resistance in experimental myocardial infarction in shock. Circ Res. 1966;19:1086-96.

18. Dormandy JA, Goetz RH, Kripke DC. Hemodynamics and coronary blood flow with counterpulsation. Surgery. 1969;65:311-20.

19. Kimura A, Toyota E, Lu S, Goto M, Yada T, Chiba Y, Ebata J, et al. Effects of intraaortic balloon pumping on septal arterial blood flow velocity waveform during severe left main coronary artery stenosis. J Am Coll Cardiol. 1996;27:810-6.

20. Lytle BW, Blackstone EH, Loop FD, Houghtaling PL, Arnold JH, Akhrass R, et al. Two internal thoracic artery grafts are better than one. J Thorac Cardiovasc Surg. 1999; 117:855-72.

21. Kurlansky PA, Williams DB, Traad EA, Carrillo RG, Schor JS, Zucker M, et al. Arterial grafting results in reduced operative mortality and enhanced long-term quality of life in octogenarians. Ann Thorac Surg. 2003;76:418-27.

22. Verma S, Szmitko PE, Weisel RD, Bonneau D, Latter D, Errett L, et al. Should radial arteries be used routinely for coronary artery bypass grafting? Circulation. 2004; 110:40-6.

23. Ruengsakulrach P, Sinclair R, Komeda M, Raman J, Gordon I, Buxton B. Comparative histopathology of radial artery versus internal thoracic artery and risk factors for development of intimal hyperplasia and atherosclerosis. Circulation. 1999;100(suppl 2):139-44.

24. Ascione R, Underwood MJ, Lloyd CT, Jeremy JY, Bryan AJ, Angelini GD. Clinical and angiographic outcome of different surgical strategies of bilateral internal mammary artery grafting. Ann Thorac Surg. 2001;72:959-65.

25. Faulkner SL, Fisher RD, Conkle DM, Page DL, Bender HW Jr. Effect of blood flow rate on subendothelial proliferation in venous autografts used as arterial substitutes. Circulation. 1975;52(suppl I):163-72.

26. Rittgers SE, Karayannacos PE, Guy JF, Nerem RM, Shaw GM, Hostetler JR, et al Velocity distribution and intimal proliferation in autologous vein grafts in dogs. Circ Res. 1978;42:792-801

27. Vural KM, Sener E, Tasdemir O. Long term patency of sequential and individua saphenous vein coronary bypass grafts. Eur J Cardiothorac Surg. 2001;19:140-4.

28. Grondin CM, Limet R. Sequential anastomoses in coronary artery grafting: technical aspects and early and late angiographic results. Ann Thorac Surg. 1977;23:1-8. 